\title{
${ }^{66}$ NOISE ANALYSIS OF SATELLITES ALTIMETRY OBSERVATIONS FOR IMPROVING CHART DATUM WITHIN THE PERSIAN GULF AND OMAN SEA,
}

\author{
Saeed Farzaneh ${ }^{1, *}$, Kamal Parvazi ${ }^{1}$ \\ (1) School of Surveying and Geospatial Engineering, College of Engineering University of Tehran, Tehran, Iran
}

Article history

Receveid January 6, 2018; accepted December 4, 2018.

Subject classification:

TOPEX/Poseidon; Jason; Noise of Satellite altimetry Observations; the Persian Gulf and Oman Sea; Chart datum.

\begin{abstract}
Sea level usually undergoes constant changes. Some of which such as tidal changes have been recognized as a part of the sea nature which possess a particular significance. In the present study, modeling of tidal variations of sea level in Persian Gulf and Oman Sea is conducted using a 22-years dataset from TOPEX/Poseidon, Jason-1 and Jason-2 altimetry missions in a conjunction with coastal tide gauge data. To do so, a time series is determined for every point of a satellite in the sea, which means that, in 772 effect points of the satellite altimetry and 7 coastal stations over sea surface, several maps, including sea level map, Datum chart map, and codomain maps of tidal components M2, S2, K1, and 01, have been presented through noise analysis and observation synthesis. In this regard, first, the structure of the functional models is investigated to examine the noise feature of satellite altimetry observations, assuming that the observations contain colored noise. It is assumed that the models are affected by combination of the following noises: 1) white-flickerrandom walk, 2) white-flicker-autoregressive, 3) white-random walk-autoregressive, 4) white-flicker-random walk-autoregressive, 5) white-flicker, 6) white-random walk, 7) flicker-random walk. Here, for statistical models of 1 to 4, the variances of autoregressive and random walk noises are estimated to be negative which reveals the inappropriateness of the random model for altimetry observations. For statistical models of 5 to 7 , the variances of these three models are estimated to be positive which reveals the appropriateness of these models. Accordingly, the analysis of maximum likelihood function for these three models was investigated. Our results show that the highest value of similarity function belongs to the structure of the second model, which indicates that the existing noise in the time series of satellite altimetry observations would be a combination of white and flicker noises. By obtaining an appropriate functional model for satellite altimetry observations, we analyzed and investigated two important components of the, mean sea level and datum chart. This analysis has been considered in two conditions: 1) the weight matrix of observations is of a unit matrix type, i.e. the existing noise model in observations is white noise, and 2) the weight matrix of observations is obtained by a combination of white and flicker noise. Finally, the resultant difference between two components of the mean sea level and the chart datum is presented. The obtained results suggest that using a precise noise model for observations at the highest level can lead to an approximate difference of $+25 \mathrm{~cm}$ and $-20 \mathrm{~cm}$, and an approximate difference of $8 \mathrm{~cm}$ on average in comparison with the condition that observations of unit weight are used.
\end{abstract}

\section{INTRODUCTION}

One of the most significant issues in hydrography operation is determining of the chart datum and converting the measured depths with respect to this base level. Cotidal chart is an altimetry reference level in hydrogra- phy which the depths inserted in the navigation charts are referred to it [Martin and Broadbent, 2004]. When choosing chart datum, the base level should be determined in such a way that at each time, available water is at least as depth shown in the chart [Ardalan and Hashemi, 2007]. 
This point is of a great importance in navigation. Also, the selected base level should not be considered in an unacceptable low position, because the minimum depth showed by this reference is much less than the actual value. Finally, this base level should be compatible with the base level of the existing adjacent chart s. In order to select such a level with the above-mentioned conditions, sea water fluctuations caused by the tide, must be determined. In the current methods of hydrography, the tide gauges installed on the coasts are used for measuring tidal changes of the sea level, and finally, the chart datum would be determined based on the lowest water level. The necessary corrections for converting the measured depths into chart datum is calculated and applied using the difference between the instantaneous sea level and the chart datum [Ardalan and Hashemi, 2007]. In the past, the mean lowest sea level (spring tide) over one year could be selected as the chart datum [Ellmer and Goffınet, 2006]. Spring tide happens whenever the gravity forces exerted by the moon and sun on the earth, become at the same direction (Hydrographic Office, 1969; The Hydrographer of the navy, 1969). In such a condition which happens on the first and fourteenth days of every lunar month, the tidal range caused by the moon is added to the tidal range induced by the sun. The important point which should be taken into account in the definition of chart datum is that under normal tidal conditions, sea water rarely reaches to a depth which is lower than the chart datum. This depth is called the Lowest Astronomical Tide (LAT) (The Hydrographer of the navy, 1969). Lowest Astronomical Tide (LAT) the lowest level that can be expected under any combination of astronomical conditions and is considered as a cotidal chart by the International Hydrographic Organization. In defining co-tidal chart the important point is that under any tidal conditions seawater is rarely lower than the co-tidal chart to ensure that water is always as deep as the amount shown in the chart. All over the world, published predictions of tidal levels are referred to the local co-tidal charts in such a way that by adding them to the depth of water shown in the diagram, the navigator reaches the total depth value. The co-tidal chart used for marine charts is considered as zero in tide gauges and tide predictions. International Hydrographic Organization recommended that the co-tidal chart be near to the Lowest Astronomical Tide level, the lowest level can be predicted under meteorological and astronomical conditions. The hydrographs were obtained in practical conditions the upper and lower astronomical conditions (that used as a co-tidal chart) with a 5 year evaluation of predicted data [Pugh and Woodworth, 2014]. Due to this fact, when developing sea chart s, the
Chart datum is selected in such a way that the sea level in the best condition stays $10 \mathrm{~cm}$ below this predefined level [The Hydrographer of the navy, 1969].

Some of researches done on analyzing sea level changes using Tide-gauges and Altimetry data are as follows:

Marc et al. [2004] calculated an estimate of the changes in sea level rising and falling of the Mediterranean using Topex Altimetry and Tide gauge stations observations and finally predicted these vertical movements using the time series derived from these two sets of observations. Kuo, Shum [2004] introduced a new method for combining both the Altimetry and Tide gauge observations, which provided better results for vertical movements and combined 25 Tide gauge stations and Topex altimetry observations based on this method.

Garcia et al. [2007] and Braitenberg et al. [2010] compared the SSH time series obtained from the Tide gauge stations, Topex altimetry and ERS-1/2 observations and expressed the difference between the Altimetry measurements and the closest Tide-guage station then provided an estimate of sea level by combining these observations. Nerem et al. studied sea level changes using Topex Altimetry and Jason observations. Church and White evaluated the average rate of sea level rising between 1980 and 2009 using tide gauge and altimetry observations. Ablain et al. [2017] used tide gauge, Topex altimetry and ERS-1/2 observations and based on this, they studied sea level at the regional and global scale, then showed that improvement is obtained in the climate system with combination of different Altimetry observations.

In the present research, we focus on the sea tidal modeling over the Persian Gulf and Oman Sea by combination of satellite altimetry observations (TOPEX-Poseidon, Jason-1, and Jason-2 from 1992 to 2014) and coastal tide gauge data from 1999 to 2010. According to the orbital structure of altimetry satellites, for each satellite footprint in the sea, a time series with a 9.9156day sampling interval has been established and the tidal effects have been modeled using least squares estimation method. Therefore, in 772 effect points of the satellite movement and 7 coastal tide gauge stations over the desired area, mean sea level (MSL), Chart datum, and the tidal model have been determined and the mean sea level map, Chart datum, co-domain maps, and tidal components $\left(\mathrm{M}_{2}, \mathrm{~S}_{2}, \mathrm{~K}_{1}\right.$, and $\left.\mathrm{O}_{1}\right)$ have been presented.

In the following, the logarithm of the likelihood function has been used, which is based on the maximum likelihood method to determine the data noise structure. Given the noise in the satellite altimetry observations, an appropriate random model was examined using a 
proper statistical model. The least squares noise estimation method has been used to estimate the noise range existing in the tidal observations.

Because of the noise significant effect on the time series and this fact that time series can always be accompanied by noise, existence of the noise in time series must be studied carefully. For this reason, another case that must be investigated in this research is the existence of the noise in the satellite altimetry observations time series. The ideal condition is when the observations are independent. Time series may have spatial and temporal correlation. If the observations do not have temporal correlation, they have white noise. But in the time series derived from altimetry satellites, temporal correlation is present, which means the existence of color noise in observations. Therefore, we must inevitably need to know the effects of other noise in observations. In the methods for estimating variance components, including MINQUE, BIQUE, Helmert, REML all relationships provide an estimate of the variance components based on the assumption that the observations have a normal distribution while LS-VCE avoids the assumption of normal distribution for observations. LSVCE method is based on the least squares principle therefore it is very flexible and it is easy to apply the least squares theory in this method. Some of the features that make using of least squares method are as follow: In this method we can provide a general class of unbiased estimators that are independent of the distribution considered for observations, minimal variance estimators even for one class of observations with elliptical distribution can be presented. In this method, covariance matrix, the estimator variance is obtained directly and conveniently. LS-VCE provides a clearer geometric interpretation of least squares, the properties of matrix Normal and orthogonality are easily established, and unstable observations and statistical tests are presented easily by this method. Finally, we can study the structure of model as if the number of considered parameters is suitable for a model or not. In other words, other methods can be considered a special case of the LSVCE method. Our observations may not follow the normal distribution and for this reason, in this paper, the LS-VCE method is used to estimate noise of time series derived from altimetry satellites observations. Next, In order to determine the noise structure of the data, the logarithm of the likelihood function which is based on the maximum likelihood method is used and the appropriate random model was studied using a valid statistical model [Amiri-Simkooei and Tiberius, 2007; Amiri-Simkooei, 2009; Amiri-Simkooei, 2007; AmiriSimkooei et al., 2014].

\section{MATERIALS AND METHODS}

\subsection{SATELLITE ALTIMETRY OBSERVATIONS}

The first studies in the context of using satellitebased techniques for sea level evaluation were raised in 1969 in Williamstown Conference of Solid Earth and Ocean Physics. Four years later in a spatial laboratory, the first sea level measurement was performed using altimetry radar S-193 with the accuracy of about $1 \mathrm{~m}$ [Cheng, 2004]. Later, various satellites were used for different space missions.

Based on continuous passes of the satellite in the definite and crossing paths from above sea, the satellite measures free sea surface level in a regular network with uniform distribution of sub-satellite points. In this research, satellite altimetry observations over different time periods, 1992-2002, 2003-2008 and 2009-2014, were used, which are derived from Topex/Poseidon, Jason-1 and Jason-2 altimetry missions, respectively (provided by the Archiving, Validation, and Interpretation of Satellite Oceanographic (AVISO) data (ftp://avisoftp.cnes.fr/AVISO/pub).

Topex/Poseidon satellite altimetry mission generated SSH measurements with RMSE yielding an accuracy better than $5 \mathrm{~cm}$ for a single-pass and better than $2 \mathrm{~cm}$ at a global scale [Chelton et al., 2001]. To eliminate atmospheric effects, this satellite was placed into high-altitude orbit, $1336 \mathrm{~km}$, to perform accurate orbit modeling [Tapley et al., 1994]. Jason-1 was a follow-on altimetric mission to the very successful TOPEX/Poseidon mission. Similarly, Jason-2 was a follow-on altimetric mission to the TOPEX/Poseidon and Jason-1 mission, with an accuracy of about $2.5 \mathrm{~cm}$ in sea level measurement, as well as Jason-1 [Rosmorduc V. et al., 2009]. In this research, along-track data from Altimetry satellites of the type Geophysical Data Record (GDR) are used. In such a way that for Topex, Jason-1 and Jason-2 Altimetry satellites, MGDR-B, MGDR-C and MGDR-D are used respectively. The instantaneous water level data taken by these three satellites has been used.

The data from Topex, Jason 1 and Jason 2 satellites have the same coverage when they are on the same orbit, and by applying intermission bias to data from Jason 1 and Jason 2 satellites (available in files Satellite data), can combine them with the Topex satellite data. For tide-gauge data, 7 tide-Gage stations are used. Observations have a half hour's Sample rate. We get these observations from Iran Mapping Organization.

\subsection{COASTAL TIDE-GAUGE OBSERVATIONS}

Coastal tide-gauges play an important role in the sea surface change modeling using satellite altimetry ob- 
servations. One of the most important advantages of using coastal tide-gauge observations is their relative high accuracy along coastlines where altimetry techniques suffer from low accuracy [Wang, Y., 2004]. Thus, the combination of these two mentioned measuring methods can reduce the rate of errors in satellite altimetry observations along coastlines.

As shown, the data have low accuracy in coasts. Hence a combination of coastal gauge-tide data and the satellite altimetry are applied to enhance the accuracy in the coasts leading to add "722" quasi- tide-gauge points via satellite altimetry observations. In this study, the observations of 7 tide-gauge stations over the area of study have been used. But when combined and comparison of Tide-Gage and Altimetry time series, it has been used for 4 years and 6 years. The information of these stations can be found in Table 1 .

$\begin{array}{cccccc}\text { Station } & \text { Longitude } & \text { Latitude } & \text { Time Interval } \\ \text { Imam Hassan port } & 50^{\circ} & 15^{\prime} & 29^{\circ} & 50^{\prime} & 1999-2009 \\ \text { Khark lsland } & 50^{\circ} & 20^{\prime} & 29^{\circ} & 16^{\prime} & 1999-2003 \\ \text { Bushehr port } & 50^{\circ} & 50^{\prime} & 28^{\circ} & 59^{\prime} & 1999-2010 \\ \text { Kangan } & 52^{\circ} & 03^{\prime} & 27^{\circ} & 50^{\prime} & 1999-2003 \\ \text { Bandarabas } & 56^{\circ} & 28^{\prime} & 27^{\circ} & 08^{\prime} & 1999-2005 \\ \text { Jask } & 56^{\circ} & 04^{\prime} & 27^{\circ} & 06^{\prime} & 1999-2005 \\ \text { Chabahar } & 57^{\circ} & 46^{\prime} & 25^{\circ} & 39^{\prime} & 1999-2005\end{array}$

TABLE 1. Tide-gauge stations used in this study.
Figure 1 illustrates the location of tide-gauge stations as well as the passes of the used altimeter satellites over our study region.

\subsection{DATA ANALYSIS}

Radar altimeters on board the satellite permanently transmit signals at high frequency to the Earth, and receive the echo from the sea surface. This is analyzed to derive a precise measurement of the round-trip time between the satellite and the sea surface. The time measurement, scaled by the speed of light (at which electromagnetic waves travel), yields a range measurement. By averaging the estimates over a second, this produces a very accurate measurement of the satellite-to-ocean range. It is worth pointing out that radar altimetry is exclusively designed for oceans because of the favorable reflectivity of the radar signals over large water bodies [Cheng, 2004].

If the satellite position in the orbit is accurately determined, the ellipsoidal height above the reference ellipsoid can be obtained by subtracting the range from the satellite altitude Thus, we can achieve the instantaneous altitude of the water surface at observation point with respect to the reference ellipsoid [Benada, 1993].

$\operatorname{SSH}(\varphi, \lambda, t)=h_{\text {sat }}(\varphi, \lambda, t)-\operatorname{Range}(\varphi, \lambda, t)$

Where $\varphi$ is the latitude at the desired point, $\lambda$ is the Longitude at the desired point, $\operatorname{SSH}(\varphi, \lambda, t)$ is the sea surface height at the desired point, $t$ indicates related time, $h_{\text {sat }}(\varphi, \lambda, t)$ is the satellite altitude with respect to the reference ellipsoid at time $t$ and $\operatorname{Range}(\varphi, \lambda, t)$ is the achieved distance between the satellite and instantaneous water surface at observation point at time $t$.

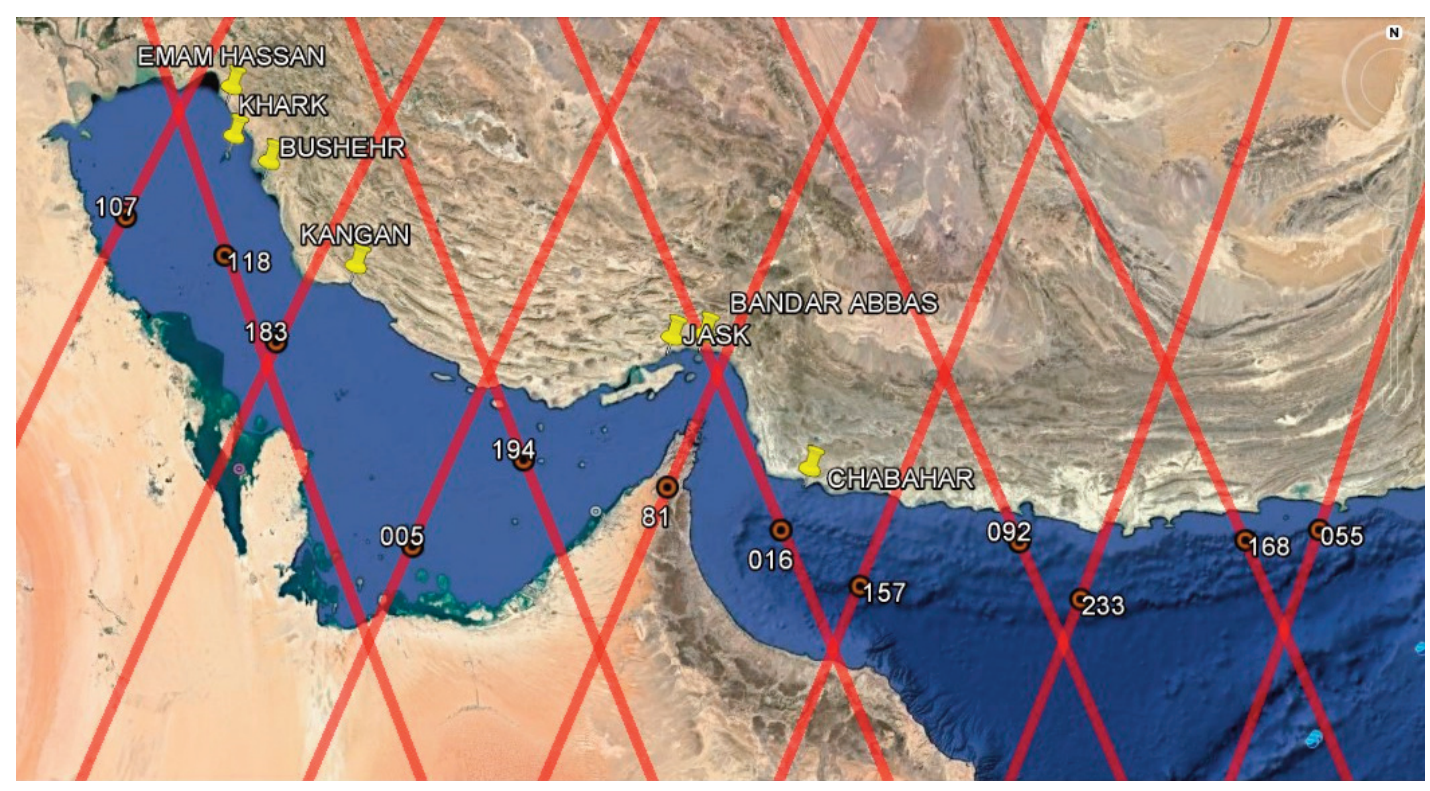

FIGURE 1. Passes of satellites T/P, Jason 1-2 and the location of tide-gauge stations. 
To determine the sea surface height at the observation point relative to the reference ellipsoid, first the distance between the satellite and sea surface measured by altimeter should be corrected to systematic errors. To eliminate these errors the following corrections are required: wet troposphere correction, dry troposphere correction, ionosphere correction, electromagnetic bias correction, ocean tide correction, inverse barometer correction, pole tide correction and center of gravity movement correction [Benada, 1993].

As one of the purposes of this research is tide modeling, the ocean tide correction has not been applied on the data. When the mentioned corrections are applied, the residual surface can be achieved as $\mathrm{SSH}+$ Tide. All the above-mentioned corrections except for the tide correction will be applied on the observations to prepare the data forming the time series. In Figure 2, the altimeter measurement method is indicated.

The signal produced by altimetry observations at a specific time can be formulated as follows [Wang, 2004; Vanicek and Krakiwsky, 1991; Boon et al., 1978]:

$U(\varphi, \lambda, t)=\sum_{j=1}^{\mathrm{K}} A_{j} \cos \left(\omega_{j} t+\theta_{j}(\varphi, \lambda)\right)$

Where parameters $A_{j}$ and $\theta_{j}$ are the amplitude and the phase of the tidal components, respectively, and $\omega_{j}$ $\omega_{j}$ is the angular velocity of the $j$-th component.

Extending cosine function, the above non-linear function is achieved as follows:

$U(\varphi, \lambda, t)=\sum_{j=1}^{\mathrm{K}}\left[a_{j}(\varphi, \lambda) \cos \left(\omega_{j} t\right)+b_{j}(\varphi, \lambda) \sin \left(\omega_{j} t\right)\right]$
Where parameters $a_{j}$ and $b_{j}$ are the amplitude of cosine and sine terms.

Theoretically, in spectral Fourier analysis, it is assumed that tide frequencies are integer values, but in practice, there is no integer frequency. Based on the equation (3), extracting parameter $S$ indicating linear sea surface variation rate is not possible, but using the linear regression in equation (4), it can be computed. $\operatorname{SSH}(\varphi, \lambda, t)$ is a time series resulted from the tide-affected water level observations Due to this fact that tide is a frequent phenomenon, this time series is formalized in the entire tide process at each point as follows:

$$
\begin{aligned}
\operatorname{SSH}(\varphi, \lambda, t) & =\operatorname{MSL}(\varphi, \lambda, t)+S(\varphi, \lambda) \times t \\
+ & \sum_{j=1}^{\mathrm{K}}\left[a_{j}(\varphi, \lambda) \cos \left(\omega_{j} t\right)+b_{j}(\varphi, \lambda) \sin \left(\omega_{j} t\right)\right]
\end{aligned}
$$

Where $\operatorname{SSH}(\mathrm{t})$ is the water altitude at time moment of $t, M S L$ is the mean time series (water level), $j=1,2,3, \ldots, k$ of the components number, $K$ is determined based on the number of applied components. And finally, $S$ is the rate of change [Les Misèrables].

If Equation (4) is rewritten for all observations at $t_{0}, t_{1} \ldots t_{n}$, the observation equation system would be formed as:

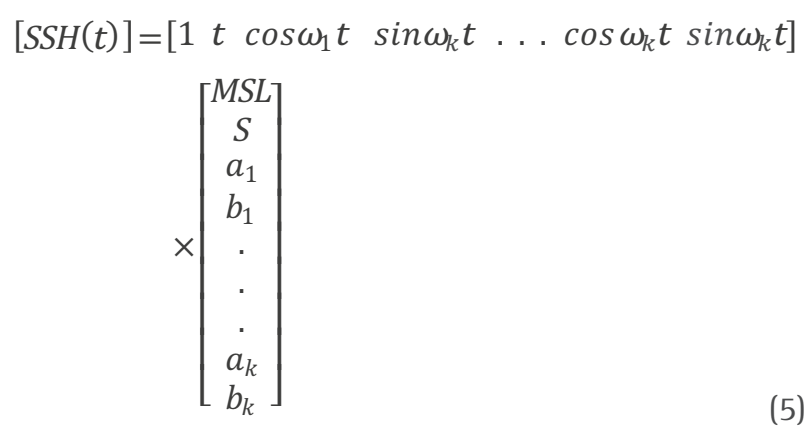

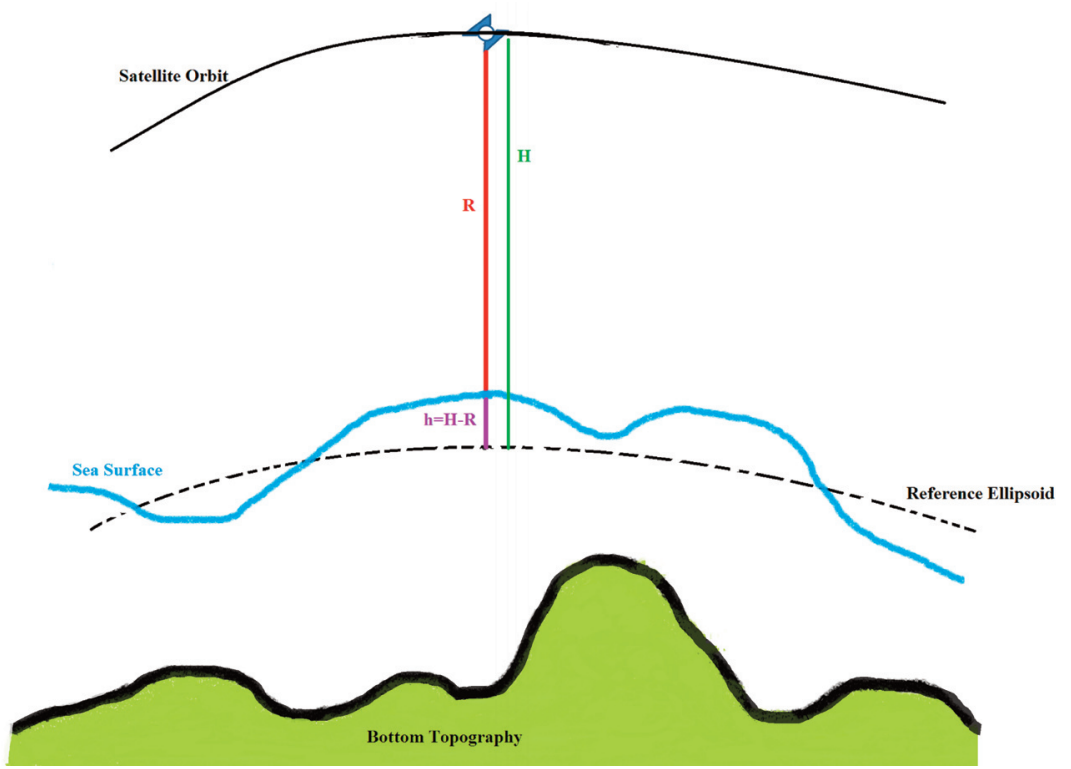

FIGURE 2. The view of quantities of altimetry satellite. 
For each point during the sampling time interval, a time series can be achieved. In the selection of components as the reference components or neighboring reference components, two points should be considered. The first one is the relative severity of components in creating tidal potentials and the second one is the measurement duration. These two points indicate that firstly, the components which more contribute to the occurred tide should be considered and secondly, the time period related to time series of the used data is a reference for extracting components with higher periods. To achieve unknown coefficients in the equation (5), the least squares method will be applied if the linear observation model equation is as follows:

$Y=A x$

In this equation, $Y$ is the observation vector (instantaneous water surface height), $A$ is the coefficients matrix, $x$ is the unknown vector including $a_{j}, b_{j}, M S L$, and $S$ computed using the following equation.

$\hat{x}=\left(A^{T} P A\right)^{-1} A^{T} P Y$

At first, we assume that our observations have a unit weight $(\mathrm{P}=\mathrm{I})$. The amplitude and phase of tidal components are computed as follows:

$$
\begin{aligned}
& A_{j}=\sqrt{a_{j}^{2}+b_{j}^{2}} \\
& \theta_{j}=\tan ^{-1}\left(\frac{b_{j}}{a_{j}}\right)
\end{aligned}
$$

Regarding an altimeter satellite with the repeated period of $d$ days, the altimeter performs a repeating observation at each point of the satellite at sea level or in each period $d$. As this repeating period in the altimeter satellites is a couple of days, the semidiurnal and diurnal components are often aliased to signals with higher periods. For example, Topex/Poseidon repeating period is 9.9156 days [Benada, 1993].

In a tide component with frequency $f_{k}$, its alias frequency, $f_{a}$, can be written as [Wang, Y., 2004]:

$f_{a}=\left|\operatorname{mode}\left(f_{k}+\frac{f_{s}}{2}, f_{s}\right)-\frac{f_{s}}{2}\right|$

Where $f_{s}=\frac{1}{P}$ is the sampling frequency of the altimeter satellite.

After detecting the major frequencies constituting the signal (as aliased frequencies) using the least squares methods, each frequency and relevant amplitude can be estimated through equation (4). Then, for estimating the related phase correctly, the equation (2) should be solved while the amplitudes and the frequencies are known. It should be pointed out that the estimated amplitudes of the previous step and real frequencies will be used in this step. Based on the results of this research, finding tidal amplitudes from the aliased frequencies are accurate enough and using real frequencies will be acceptable for finding phases.

Our attitude toward forming time series for observations in the tide-gauge stations is in the same order as the altimetry observation but in this case, there is no restriction on the long duration of 9.9156 days between observations. In this case, we can use the possibly small distance (high separation capability) for discretization of measurements or continuous records of a tide-gauge system. As it has been mentioned, satellite altimetry data don't enjoy high accuracy in proximity to the land areas. Using tide-gauge observations, this accuracy can be improved. The observations in tide-gauges are compared to zero and to refer them to the reference ellipsoid, coastal benchmark height with respect to the reference ellipsoid is added to the observations.

The equation 4 is formulating the changes of sea level with altimetry satellites and tide-gauge including unknown parameters (tidal parameters and mean sea level) with equal definitions. Thus, the estimated tide parameters and the mean sea level from two math models can be combined.

To combine satellite altimetry data with coastal tidegauge observations for estimating tidal parameters such as the mean sea level, the common datum for satellite observations and tide-gauges are required. The satellite altimetry observations are dedicated to the $\mathrm{T} / \mathrm{P}$ reference ellipsoid, while the tide-gauge observations are dedicated to zero systems or benchmark reference of the station. Based on the numerous observations or altimetry data against tide-gauge data, the reference ellipsoid of the satellite altimetry technique is selected as a common datum. Thus, the tide-gauge data should be transferred to a common datum. To do this, the height of the benchmarks should be transformed from geoid reference to the reference ellipsoid of the radar altimetry and the relevant observations are corrected in tide-gauges.

To compute the amplitude and the phase of main components of tide (solar and lunar semi-diurnal and diurnal components), as a period of satellite data is about 9.9156 days, the frequencies are assumed to be known. However, for coastal tide-gauges, the frequencies are extracted from the data and are used in the model [AmiriSimkooei et al., 2014]. 
Table 2 shows the data of 10 components with a short period, 12 semi-diurnal components, 10 diurnal components and 6 components with long periods which are the main tide components as applied in this research [Amiri-Simkooei et al., 2017; Amiri-Simkooei et al., 2014; House, 1995; Wahr, 1995].

The algorithm of tide modeling using satellite altimetry observations can be expressed as follows:

1. Applying the systematic corrections mentioned in chapter one on the altimetry data.

2. Forming a 9.9156-day time series for every spotted point on the sea surface (number of points in the Gulf of Oman and the Persian Gulf: 772).

3. Filling the missing data using available methods.

4. Using least square harmonic estimation analysis to find the existing frequencies in the time series (find- ing the frequency of waves with periods higher than 19.83 days).

4.1 Using the least squares estimation to achieve accurate frequencies, range and wave phase.

4.2 Removing the effect of the waves with ranges higher than the observations accuracy.

4.3 Sorting the data based on the 2.04-hour time interval during the day and the night.

4.4 Using least square harmonic estimation analysis to find the existing frequencies in the time series (finding the frequency of waves with periods higher than 4.08 days).

4.5 Using proration of least squares to achieve accurate frequencies, range and wave phase.

4.6 Removing the effect of the waves with ranges higher than the observations accuracy.

\begin{tabular}{|c|c|c|c|c|c|}
\hline No. & Tidal component & Period (hours) & No. & Tidal component & Period (hours) \\
\hline 1 & M4 & 6.21030065307521 & 20 & 2SM2 & 11.6069200457312 \\
\hline 2 & M6 & 4.14019700713438 & 21 & $\mathrm{~L} 2$ & 12.1915685550187 \\
\hline 3 & MK3 & 8.17712302645135 & 22 & $\mathrm{~K} 2$ & 11.9673482869339 \\
\hline 4 & S4 & 6.00001320002904 & 23 & Lunar diurnal $\mathrm{K} 1$ & 23.9345533572998 \\
\hline 5 & MN4 & 6.26916405085796 & 24 & Lunar diurnal 01 & 25.8193779595462 \\
\hline 6 & S6 & 4 & 25 & Lunar diurnal 001 & 22.3059438648616 \\
\hline 7 & M3 & 8.28042144032962 & 26 & Solar diurnal S1 & 23.9984832958557 \\
\hline 8 & $2 \mathrm{MK} 3$ & 8.3863 & 27 & M1 & 24.8412 \\
\hline 9 & M8 & 3.10515225493051 & 28 & $\mathrm{~J} 1$ & 23.0984223777516 \\
\hline 10 & MS4 & 6.10334426645736 & 29 & $\rho$ & 26.7230 \\
\hline 11 & Principal lunar semidiurnal M2 & 12.4206013061504 & 30 & Q1 & 26.8681419067782 \\
\hline 12 & Principal solar semidiurnal S2 & 12.0000336000940 & 31 & 2Q1 & 28.0062224337028 \\
\hline 13 & $\mathrm{~N} 2$ & 12.6582919407186 & 32 & Solar diurnal P1 & 24.0659985945456 \\
\hline 14 & $v 2$ & 12.626 & 33 & Solar annual Sa & 8766.231773908 \\
\hline 15 & MU2 & 12.8717191596826 & 34 & Solar semiannual SSa & 4382.906489375 \\
\hline 16 & $2 \mathrm{~N} 2$ & 12.9053739267568 & 35 & MSM & 763.4865314867 \\
\hline 17 & $\lambda 2$ & 12.221 & 36 & Lunar monthly Mm & 661.3092680245 \\
\hline 18 & $\mathrm{~T} 2$ & 12.0164433010131 & 37 & MSF & 354.3670619784 \\
\hline 19 & $\mathrm{R} 2$ & 11.9835957899394 & 38 & MF & 327.8589844410 \\
\hline
\end{tabular}

TABLE 2. The data of 38 main components of tide. 
4.7 Investigating the remnants and finally forming the model.

\subsection{CHART DATUM}

There are various methods to definition chart datum. Longer observations have acceptable values of this surface. Chart datum regionally depends upon the behavior and nature of the tide in the region. In Figure 3 the different tidal levels is indicated.
The common method to use chart datum is using tide-gauge observations. Due to the high difference between amplitude and phase of the tide in various regions, this method is not suitable to determine the chart datum in the off-shore areas and some other methods should be applied. Therefore, the combination of these two kind of observations (satellite altimetry observations and coastal tide gauge observations) is applied in this research.

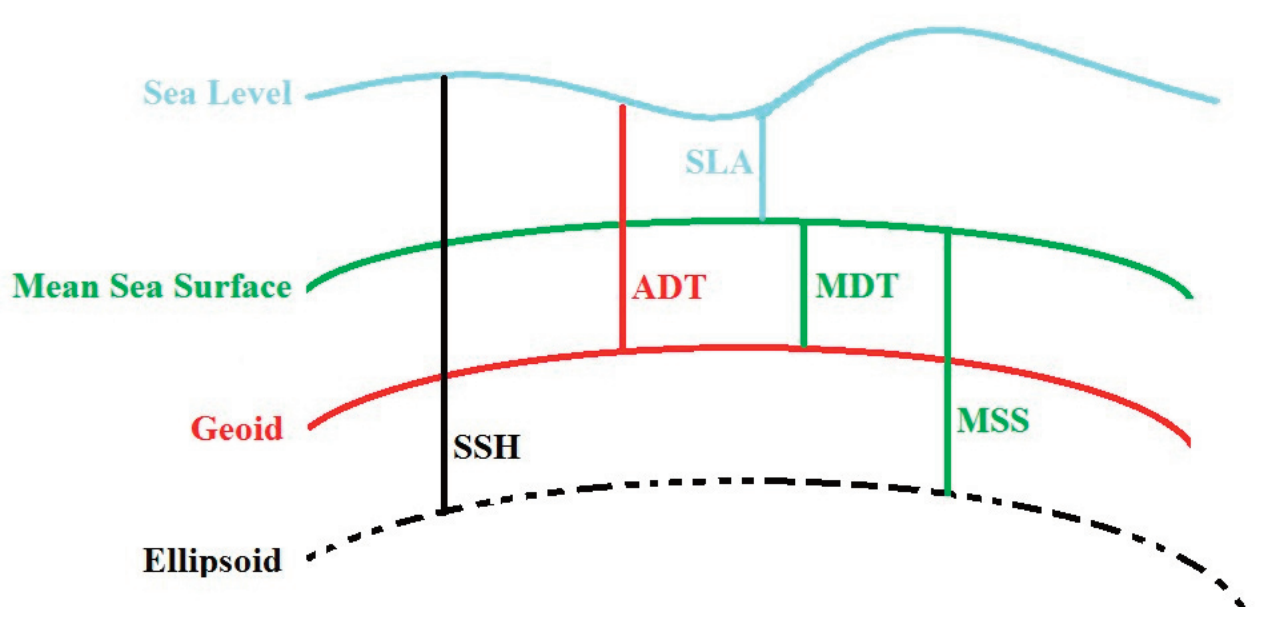

FIGURE 3. The various levels of tide.

To compute chart datum, the Indian spring low water (I.S.L.W.) is used which a level of water is proposed by George Darvin as Indian Ocean chart datum. This level is achieved using the difference between the sum of main components amplitude of lunar and solar semidiurnal, and diurnal components of sea level as shown in the following equation [The Hydrographer of the navy, 1969]:

$I S L W=Z_{0}-(M 2+S 2+K 1+O 1)$

Where, $Z_{0}$ is mean sea level and M2, S2, K1, and 01 are the amplitude of main components of semi-diurnal and diurnal components.

The chart datum determined by this method is suitable for most regions throughout the world including south and west of the Persian Gulf and some parts of India and Malaysia. In common hydrography methods, after the harmonic analysis of data related to installed stations in the shores, the amplitude of main tide components is computed (semi -diurnal and diurnal) and finally, various equations as follows are used based on the tide behavior to calculate the chart datum altitude with respect to the zero coastal tide-gauge:

$h_{C D}=M S L-1.1\left(M_{2}+S_{2}+K_{1}+O_{1}\right)$
After computing the considered unknown values for main tide components and achieving amplitude of these components, the following equation will be applied [Ellmer and Goffinet, 2006] to compute the separation of chart datum with respect to the reference ellipsoid WGS84 the Persian Gulf and Oman Sea:

$$
\begin{aligned}
h_{C D}(\varphi, \lambda)=M S L & \\
& -\left[\sum_{j=1}^{k} \sqrt{a_{j}^{2}(\varphi, \lambda)+b_{j}^{2}(\varphi, \lambda)}\right]
\end{aligned}
$$

The selection of the $\mathrm{k}$ value (number of applied components) depends on various factors including time span of observations and amplitude of components affecting the studied region considerably.

Since the altimetry observations are relative to elliptical base level and the tide gauge observations are relative to the local base level, we must consider a datum transform. For this purpose, we consider the elliptical base level as the reference level for both cases. Therefore, we must transform the tide-gauge observations to the elliptical base level. In Figure 4, the relationship between the different base level is shown. 


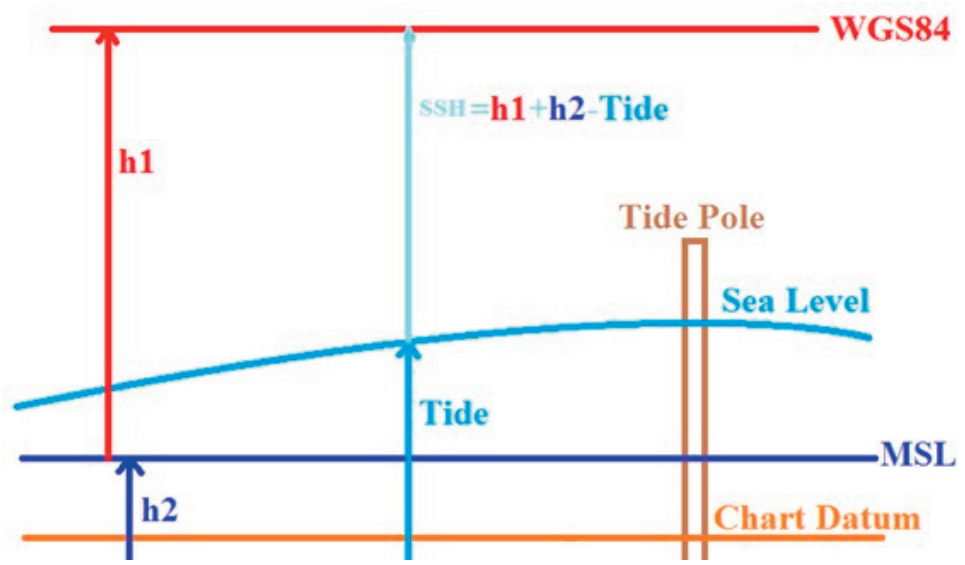

FIGURE 4. Relationship between the different base level.

\subsection{THE LEAST SQUARES NOISE ESTIMATION}

Based on the noise in satellite altimetry observations, the least squares noise estimation method will be applied to estimate the amplitude of the noise in the tide observations.

The least squares noise estimation method was presented by Teunissen [1988]. The linear model of observation equations is written as:

$E(\underline{y})=A x, D(\underline{y})=Q_{y}=\sum_{k=1}^{P} \sigma_{k} Q_{k}$

Where the covariance matrix, $Q_{y}$, is a positive-definite matrix and is denoted as an unknown linear composition from known cofactor matrices $Q_{k}$. The co-factor matrices with $m \times m$ dimensionality are assumed symmetrical in a way that the sum of the series components in the equation 14 is a positive-definite matrix. The necessary condition to obtain a regular answer for the random model is that cofactor matrices be independent and linear. The least squares estimation of the p dimensionality vector including unknown covariance components in the random model of the observations, $\underline{\hat{\sigma}}$ can be achieved using the following equation: $\underline{\hat{\sigma}}=N^{-1} \underline{l}$

Where the elements of matrix $\mathrm{N}$ with $p \times p$ dimensionality and vector $\underline{l}$ with $\mathrm{p}$ dimensionality are achieved via the following equations [Amiri-Simkooei, 2007]:

$$
\begin{aligned}
& n_{k l}=\frac{1}{2} \operatorname{tr}\left(Q_{y}^{-1} P_{A}^{\perp} Q_{y}^{-1} P_{A}^{\perp} Q_{l}\right) \\
& \underline{l}_{k}=\frac{1}{2} \underline{\hat{e}}^{T} Q_{y}^{-1} Q_{k} Q_{y}^{-1} \underline{\hat{e}}, \quad k, l=1,2, \ldots, p
\end{aligned}
$$

Due to the presence of $Q_{y}$ matrix in the equations 16 , 17 , a repetitive process is used to estimate covariance elements. At first, an initial value is considered for covariance components and in each step of repetition, their new estimations are achieved and replaced with the previous values. This repetitive trend is continued until the estimated value for covariance components remains unvaried in spite of more repetition [Amiri-Simkooei, 2007].

\subsection{RANDOM MODEL DETERMINATION FOR TIME SERIES}

Before using the least squares noise estimation method, defining the structure of the existing noise in observations is essential. Determining a suitable structure for the random model is possible using likelihood function logarithm. Using this solution, we can decide which noise can be present in the random model structure.

To determine the structure of data noise, the likelihood function logarithm can be used based on the maximum likelihood method. According to this method, if observations vector, $y$, has a multivariate normal distribution as follows:

$\underline{y} \sim N\left(A x, \sum_{k=1}^{P} \sigma_{k} Q_{k}\right)$

Then, the likelihood function logarithm of the vector is [10]:

$$
\begin{aligned}
\ln L(y ; x, \sigma)= & \frac{-m}{2} \ln 2 \pi-\frac{1}{2} \ln \operatorname{det}\left(Q_{y}\right)+ \\
& -\frac{1}{2}(y-A x)^{T} Q_{y}^{-1}(y-A x) \\
& =\frac{-m}{2} \ln 2 \pi-\frac{1}{2} \ln \operatorname{det}\left(Q_{y}\right)-\frac{1}{2} \hat{e}^{T} Q_{y}^{-1} \hat{e}
\end{aligned}
$$

In this method, the amplitude of different noises is estimated in the first step and then the probability of 
their presence in the observation is investigated. After estimating different $Q_{y}$ s correspond to different $C_{y} \mathrm{~s}$, they can be placed into the equation 19 and finally, covariance matrix, $Q_{y}$ is selected and subsequently, the highest value for likelihood function logarithm is achieved. The important point that should be taken into account is the type of the existing noise in the observation. The ideal states show that however observations are independent, but time series can have spatial and temporal correlations. If observations have no temporal correlation, it is white noise. In the time series of satellites altimetry and coastal tide-gauge observations, a temporal correlation exists indicating colored noise in the observations. Thus, we have to know the effect of other noises on the observations achieved by the use of statistical models. In this study, the noise of time series of satellite altimetry observations and coastal tide-gauge data are investigated by the Least Square Variance Component Estimation (LS-VCE) considering the 7 following statistical models and estimated variance components. The applied statistical models include:

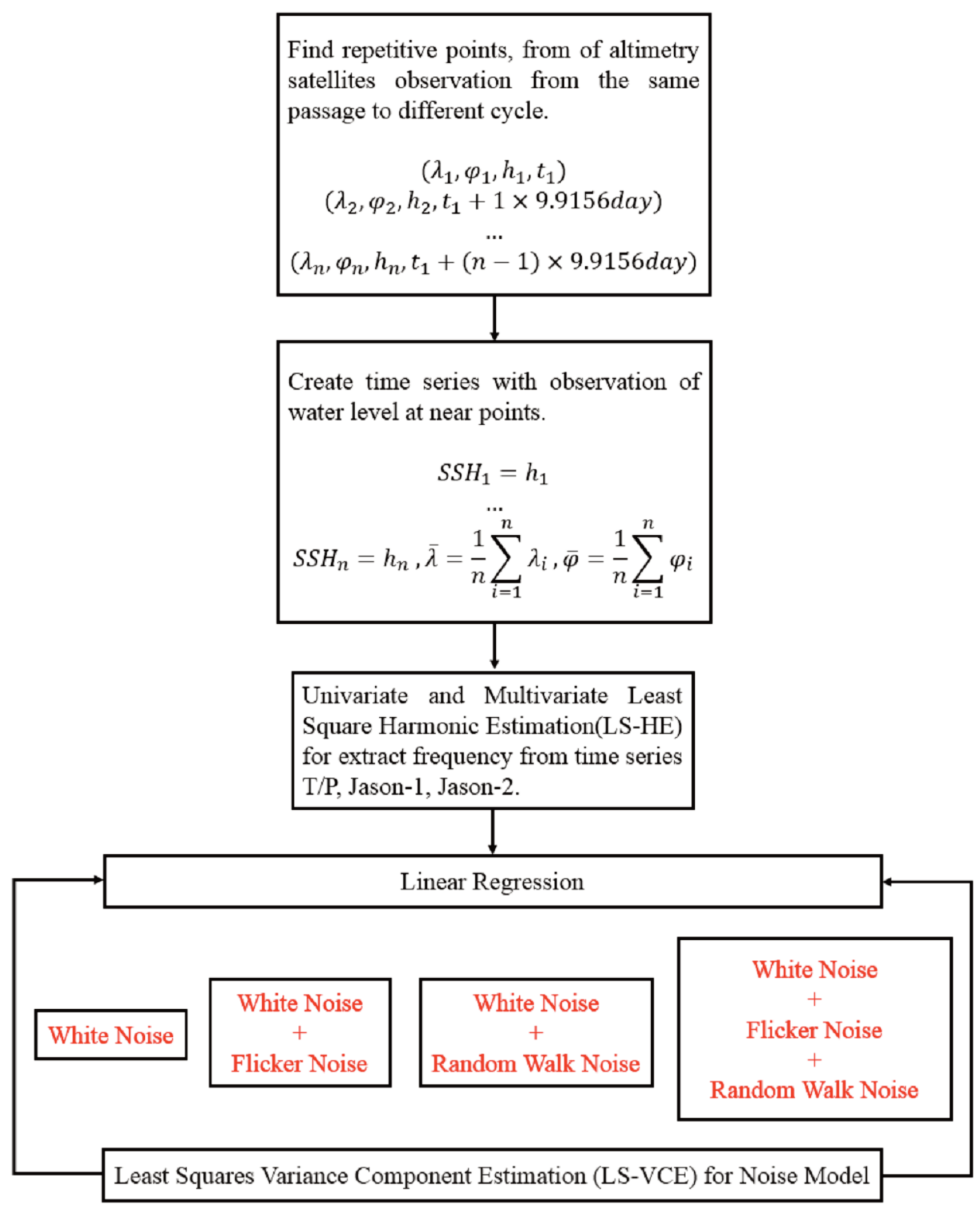

FIGURE 5. How to create time series, extract frequency and least square variance component estimation. 
White noise $\left(Q_{y}=\sigma_{w} I\right)$, White noise + Flicker noise $\left(Q_{y}=\sigma_{w} I+\sigma_{f} Q_{f}\right)$, White noise + Random walk noise $\left(Q_{y}=\sigma_{w} I+\sigma_{r w} Q_{r w}\right)$, Random walk noise + Flicker noise + White noise $\left(Q_{y}=\sigma_{w} I+\sigma_{f} Q_{f}+\sigma_{r w} Q_{r w}\right)$, White noise + Flicker noise + Autoregressive noise $\left(Q_{y}=\sigma_{w} I\right.$ $+\sigma_{f} Q_{f}+\sigma_{A r} Q_{A r}$ ), White noise+ Random walk noise+ Autoregressive noise $\left(Q_{y}=\sigma_{w} I+\sigma_{r w} Q_{r w}+\sigma_{A r} Q_{A r}\right)$, White noise+ Random walk noise + Flicker noise+ Autoregressive noise $\left(Q_{y}=\sigma_{w} I+\sigma_{f} Q_{f}+\sigma_{r w} Q_{r w}+\right.$ $\left.\sigma_{A r} Q_{A r}\right)$.

The maximum likelihood technique is applied to evaluate the results. The likelihood function for the structure of the second model has the highest value and we can say that the existing noise in time series is based on the altimetry satellite observations and the coastal tide-gauge stations combined of white noise and flicker noise.

Based on the calculation principles mentioned in section 3-2, the tidal analysis was conducted in 772 cells formed at the foot of the altimeter satellite and 7 coastal tide-gauges. The major components extracted from this analysis include 4 tidal components, namely solar half-day $\left(\mathrm{S}_{2}\right)$, lunar half-day $\left(\mathrm{M}_{2}\right)$, solar daily $\left(\mathrm{K}_{1}\right)$, lunar daily $\left(\mathrm{O}_{1}\right)$. Results of the analysis of time series obtained from the satellite altimetry and coastal tidegauges are presented in the Table 3 .

In this table, the range of all the important daily and half-day components, main short period components, and long period components are shown. Table 4 shows the range variations of the components extracted from satellite altimetry and coastal tide-gauges observations. In Figure 5, the data processing process is presented.

Figure 6 shows the co-domain map of the solar half-day tidal component with a 12-hour interval. For the preparation of this map, the data from both coastal tide gauges within the Persian Gulf and Oman Sea and the data in a 22-year interval from satellite altimetry observations have been used together. As can be seen in figures 6 to 9, the tidal behavior in the Persian Gulf is completely different from the tidal behavior observed in the Gulf of Oman. For justifying this issue, it should be explained that the Persian Gulf is a very low-depth water field with a mean depth of $25 \mathrm{~m}$. The depth of this Gulf leads to susceptibility to weather conditions and its small dimensions intensify tidal components. As can be seen in the following figure, this issue is also true about other tidal components. In this calculation, due to the dissimilarity of the height base of the coastal tide gauges and satellite altimetry data, a homogenization of the base level has been conducted first and then the possibility of their integration has been created.

Figure 7 shows the co-domain map of the tidal component lunar half-day $\left(\mathrm{M}_{2}\right)$ with a 12.42-hour interval.

Figure 8 illustrates the co-domain map of the tidal component solar daily $\left(\mathrm{K}_{1}\right)$ with a 23.93-hour interval.

Figure 9 indicates the co-domain map of the tidal component lunar daily $\left(0_{1}\right)$ with a 25.81-hour interval.

\begin{tabular}{|c|c|c|c|c|c|c|c|}
\hline $\begin{array}{l}\text { Constituent } \\
\text { name }\end{array}$ & $\begin{array}{c}\text { Mean } \\
\text { Value }(\mathrm{m})\end{array}$ & $\begin{array}{c}\operatorname{Min} \\
\text { values(m) }\end{array}$ & $\begin{array}{c}\operatorname{Max} \\
\text { values(m) }\end{array}$ & $\begin{array}{c}\text { Constituent } \\
\text { name }\end{array}$ & $\begin{array}{c}\text { Mean } \\
\text { value }(\mathrm{m})\end{array}$ & $\begin{array}{c}\text { Min } \\
\text { values(m) }\end{array}$ & $\begin{array}{c}\text { Max } \\
\text { values(m) }\end{array}$ \\
\hline M2 & 0.465 & 0.0081 & 1.132 & S1 & 0.045 & 0.0014 & 0.155 \\
\hline K1 & 0.291 & 0.0166 & 0.442 & S1 & 0.042 & 0.0011 & 0.194 \\
\hline S2 & 0.164 & 0.0192 & 0.283 & Q1 & 0.041 & 0.0014 & 0.133 \\
\hline 01 & 0.155 & 0.0097 & 0.261 & MS4 & 0.037 & 0.0007 & 0.167 \\
\hline $\mathrm{N} 2$ & 0.115 & 0.0110 & 0.214 & $\mathrm{R} 2$ & 0.037 & 0.0012 & 0.140 \\
\hline K2 & 0.058 & 0.0029 & 0.178 & MN4 & 0.035 & 0.0007 & 0.312 \\
\hline P1 & 0.082 & 0.0061 & 0.156 & $\mathrm{~T} 2$ & 0.032 & 0.0001 & 0.142 \\
\hline SA & 0.057 & 0.0025 & 0.267 & MK3 & 0.032 & 0.0012 & 0.137 \\
\hline$v 2$ & 0.045 & 0.0011 & 0.178 & $\mathrm{~J} 1$ & 0.030 & 0.0008 & 0.136 \\
\hline MSL & -32.382 & -46.154 & -17.396 & Chart datum & -34.034 & -48.005 & -18.463 \\
\hline
\end{tabular}

TABLE 3. Components obtained from the altimetry satellites TOPEX-Poseidon, Jason-1, Jason-2, and coastal tide gauges. 


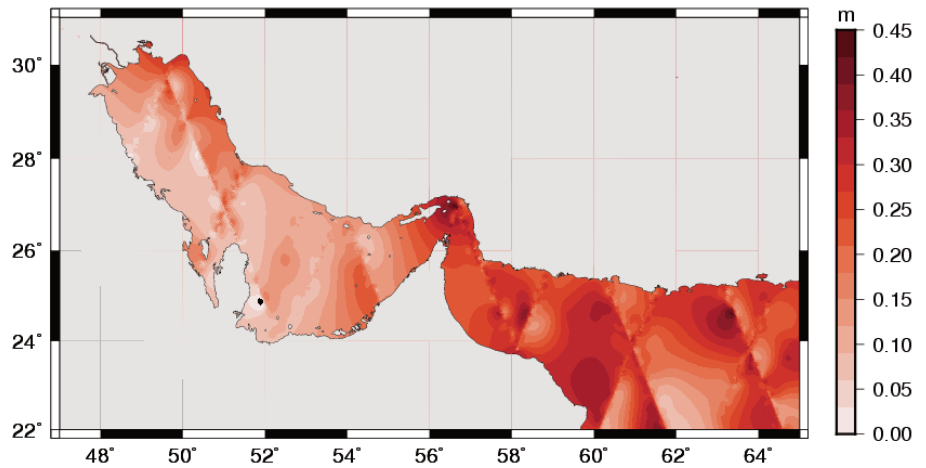

FIGURE 6. The co-domain map of the side component solar half-day $\left(\mathrm{S}_{2}\right)$ in meters.

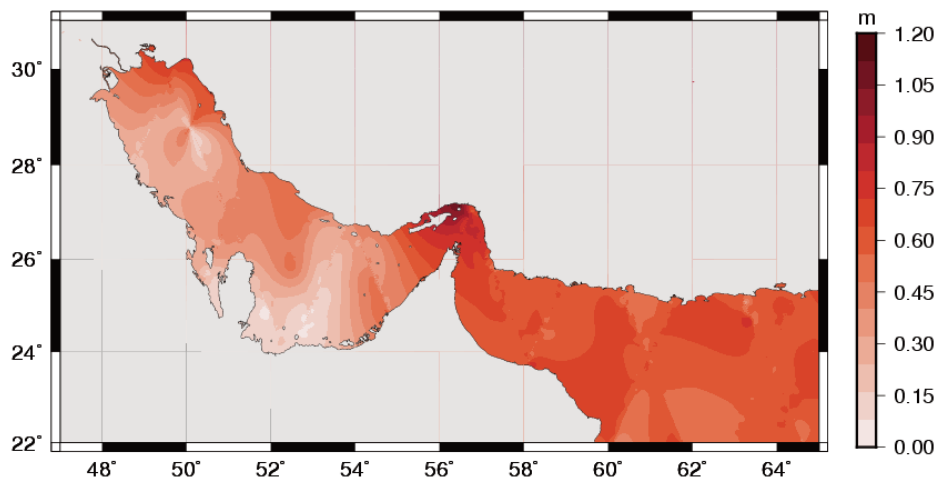

FIGURE 7. The co-domain map of the tidal component lunar half-day $\left(\mathrm{M}_{2}\right)$ in meters.

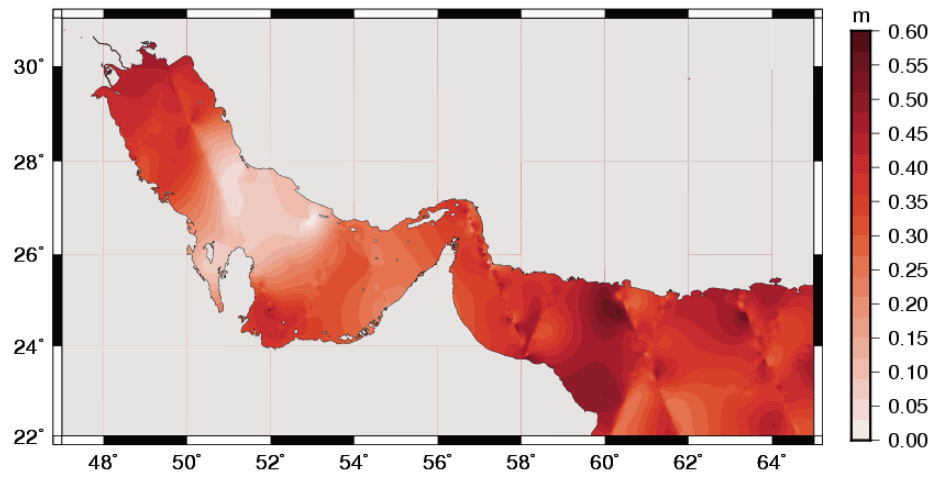

FIGURE 8. The co-domain map of the tidal component solar daily $\left(\mathrm{K}_{1}\right)$ in meters.

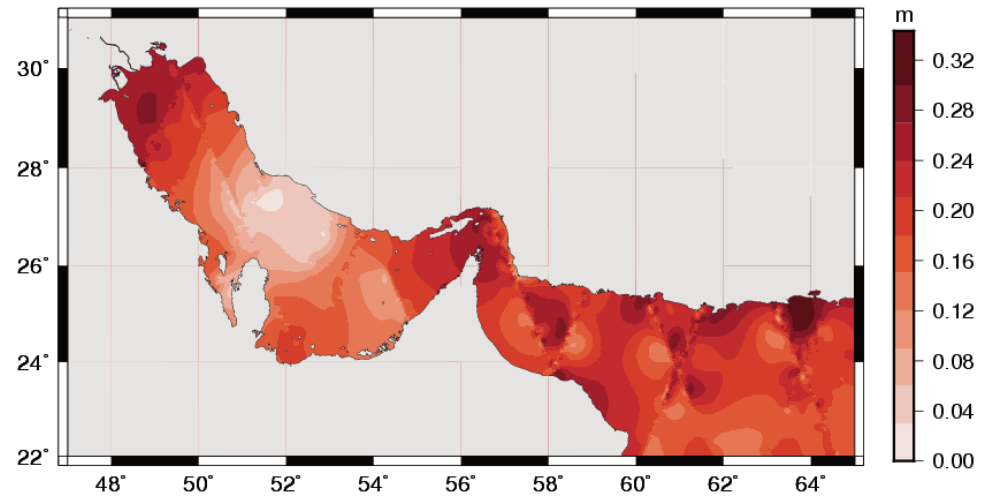

FIGURE 9. The co-domain map of the tidal component lunar daily $\left(0_{1}\right)$ in meters. 
Referring to Table 4 and, 18 tidal components considered in this table, and based on the satellite altimetry observations from TOPEX-Poseidon, Jason-1, Jason-2, and 7 coastal tide-gauges (in latitude range of 22.0091 to 29.9581 degrees and longitude range of 48.7684 to 64.5766 degrees), we conclude that 4 tidal components $\mathrm{O}_{1}(15 \mathrm{~cm}), \mathrm{S}_{2}(16 \mathrm{~cm}), \mathrm{K}_{1}(29 \mathrm{~cm})$, and $\mathrm{M}_{2}$ $(46 \mathrm{~cm})$ have the highest effects over the Persian Gulf and Oman Sea.

\begin{tabular}{ccccc} 
Station & $\begin{array}{c}\text { Tidal } \\
\text { amplitude } \\
\mathrm{M}_{2} \text { (centimeter) }\end{array}$ & $\begin{array}{c}\text { Tidal } \\
\text { amplitude }\end{array}$ & $\begin{array}{c}\text { Tidal } \\
\text { (centimeter) }\end{array}$ & $\begin{array}{c}\text { Tidal } \\
\text { amplitude }\end{array}$ \\
$\begin{array}{c}\text { k (centimeter) } \\
\text { amplitude } \\
\mathrm{O}_{1} \text { (centimeter) }\end{array}$ \\
$\begin{array}{c}\text { Bandar } \\
\text { Abbas }\end{array}$ & 38 & 16 & 34 & 22 \\
$\begin{array}{c}\text { Kangan } \\
\text { Jask }\end{array}$ & 57 & 25 & 44 & 18 \\
Khark & 35 & 12 & 27 & 11 \\
Chabahar & 67 & 25 & 43 & 18 \\
$\begin{array}{c}\text { Emam } \\
\text { Hasan }\end{array}$ & 23 & 9 & 29 & 32 \\
\hline
\end{tabular}

TABLE 4. The range of main tidal components in 7 tide gauge stations in centimeters using coastal tide gauge observations.

At some of the calculating points located near the tide gauges, results of time series analysis from satellite altimetry and coastal tide-gauges were evaluated and compared. In order to make this comparison, the data from 7 tide-gauge stations have been used. Accordingly, in order to compare the components obtained from satellite altimetry with tide gauge station, it is necessary to calculate the range of all four main components in the tide-gauge stations and they should be compared with the components achieved from satellite altimetry.

It should be noted that the least weighted squares method has been used in to compare satellite altimetry observations with tide-gauge observations; so that for the satellite time series around the tide-gauge stations, weighting has been conducted according to their distance from the tide-gauge stations. After these calculations, a time series has been created corresponding to the tide gauge station resulted from satellite observations. The above-mentioned results and the comparison of two series of information obtained from the tide gauge and the satellite altimetry have been presented in tables 4 to 6 . Among the factors which have led to a differences between the coastal tide gauges results and the satellite altimetry observations, one factor which contribute to the situation is the low accuracy of the satellite altimetry observations with respect to the tide gauge observations, and the other factor is the distance between satellite passages with the considered observation. Moreover, the satellite data don't cover the Persian Gulf and Oman Sea entirely, therefore, the idea of combining satellite and tide gauge data can solve this problem to a large extent.

\begin{tabular}{|c|c|c|c|c|}
\hline Station & $\begin{array}{c}\text { Tidal } \\
\text { amplitude } \\
\mathrm{M}_{2} \text { (centimeter) }\end{array}$ & $\begin{array}{c}\text { Tidal } \\
\text { amplitude } \\
\mathrm{S}_{2} \text { (centimeter) }\end{array}$ & $\begin{array}{c}\text { Tidal } \\
\text { amplitude } \\
\mathrm{K}_{1} \text { (centimeter) }\end{array}$ & $\begin{array}{c}\text { Tidal } \\
\text { amplitude } \\
\mathrm{O}_{1} \text { (centimeter) }\end{array}$ \\
\hline Bushehr & 26 & 11 & 30 & 20 \\
\hline $\begin{array}{c}\text { Bandar } \\
\text { Abbas }\end{array}$ & 92 & 30 & 37 & 25 \\
\hline Kangan & 41 & 12 & 9 & 5 \\
\hline Jask & 69 & 31 & 36 & 28 \\
\hline Khark & 58 & 21 & 42 & 18 \\
\hline Chabahar & 61 & 31 & 49 & 26 \\
\hline $\begin{array}{l}\text { Emam } \\
\text { Hasan }\end{array}$ & 63 & 22 & 44 & 29 \\
\hline
\end{tabular}

TABLE 5. The range of main tidal components in 7 tide gauge stations in centimeters using 22-year observations of satellites TOPEX-Poseidon, Jason-1, and Jason-2.

\begin{tabular}{ccccc} 
Station & $\begin{array}{c}\text { Tidal } \\
\text { amplitude } \\
\mathrm{M}_{2} \text { (centimeter) }\end{array}$ & $\begin{array}{c}\text { Tidal } \\
\text { amplitude } \\
\mathrm{S}_{2} \text { (centimeter) }\end{array}$ & $\begin{array}{c}\text { Tidal } \\
\text { amplitude } \\
\mathrm{K}_{1} \text { (centimeter) }\end{array}$ & $\begin{array}{c}\text { Tidal } \\
\text { amplitude } \\
\mathrm{O}_{1} \text { (centimeter) }\end{array}$ \\
$\begin{array}{c}\text { Bushehr } \\
\text { Bandar } \\
\text { Abbas }\end{array}$ & 12 & 5 & 4 & 2 \\
$\begin{array}{c}\text { Kangan } \\
\text { Jask }\end{array}$ & 16 & 5 & 7 & 7 \\
Khark & 23 & 9 & 18 & 6 \\
$\begin{array}{c}\text { Chabahar } \\
\text { Emam }\end{array}$ & 6 & 6 & 6 & 10 \\
Hasan & 40 & 13 & 15 & 3 \\
\hline
\end{tabular}

TABLE 6. The range difference of main tidal components calculated using tidal stations and satellite altimetry data in 7 tidal stations in centimeters in the Persian Gulf and Oman Sea. 
Due to the long distance of satellites passages, lack of information over the Persian Gulf and Oman Sea, and the low accuracy of the satellite observations near the coasts, the results have not been satisfactory enough, and in order to reach better results, integration of the data from tidal stations in coasts and the satellite altimetry information have to be used.

After examining the least squares variance components estimation method and the structure of functional and statistical models of time series resulted from the satellite altimetry observations, the observations related to time series of 772 points in the region of study have been investigated. In the most cases, the statistical model has been considered as the following noise combinations: 1- white, flicker, and random walk, 2white, flicker, and autoregressive, 3- white, random walk, and autoregressive, and 4- white, flicker, random walk, and autoregressive. The variance of autoregressive and random walk noises has been estimated to be negative indicating the inappropriateness of the statistical model. Therefore, the result evaluation has been conducted by maximum likelihood method for the following three conditions: 1 - white noise, 2 - white and flicker noises, and 3- white and random walk noises. The similarity function has the highest value for the structure of the second model, and it can be concluded that the existing noise in time series resulted from the satellite altimetry observations is a combination of white and flicker noises. Therefore, the combination of white and flicker noises can be used as an appropriate statistical model. For instance, for some time series of passage 5 related to the satellites used in the present research, the results have been presented in the Table 7.

First, two important components are analyzed and examined including the mean sea level and the chart datum, so that in this condition, the matrix of observations weight has been considered as a unit matrix; in other words, the model of the existing noise in the observations has been considered as a white noise. Figures 10 and 11 indicate the maps of the mean water level and the chart datum in the region of study, respectively, considering the existing noise in the observations to be a white noise. In order to the mean water level and the chart datum, a 22-year period of data from satellite altimetry and coastal tide gauges have been used.

To evaluate the existing noise structure in the time series of the satellite altimetry observation, 772 time series from a 22-year period of the tidal data were used. In order to estimate the noise of tidal observations, the least squares method was used in accordance with the equations 16 and 17. The functional model has been considered as the combination of a linear trend and 145 periodic signals, and the frequencies related to these periodic signals equal 145 main astronomical frequencies recognized for the tide. According to the determination of the appropriate model for the noise of the satellite altimetry observation, the actual mean sea level, and chart datum have been shown in Figures 12 and 13, considering the existing noise in the observations over the region.

\begin{tabular}{|c|c|c|c|c|c|c|c|c|c|c|}
\hline Model & Noise & point & 1 & 2 & 3 & 4 & 5 & 6 & 7 & 8 \\
\hline \multirow[t]{2}{*}{ WN } & WN & $\hat{\sigma}$ (meter) & 1.032 & 0.020 & 0.020 & 0.020 & 0.020 & 0.020 & 0.021 & 0.019 \\
\hline & & MLE & 311 & 444 & 443 & 445 & 453 & 442 & 438 & 458 \\
\hline \multirow[t]{3}{*}{$\mathrm{WN}+\mathrm{FN}$} & WN & $\hat{\sigma}$ (meter) & 0.031 & 0.019 & 0.019 & 0.020 & 0.019 & 0.019 & 0.020 & 0.018 \\
\hline & $\mathrm{FN}$ & $\hat{\sigma}$ (meter) & 0.012 & 0.009 & 0.012 & 0.009 & 0.008 & 0.0149 & 0.017 & 0.014 \\
\hline & & MLE & 327 & 455 & 449 & 457 & 462 & 453 & 447 & 465 \\
\hline \multirow[t]{3}{*}{$W N+R W N$} & WN & $\hat{\sigma}$ (meter) & 0.030 & 0.019 & 0.018 & 0.019 & 0.019 & 0.018 & 0.019 & 0.017 \\
\hline & RWN & $\hat{\sigma}$ (meter) & 0.003 & 0.002 & 0.003 & 0.003 & 0.002 & 0.005 & 0.003 & 0.004 \\
\hline & & MLE & 316 & 449 & 446 & 447 & 456 & 448 & 441 & 462 \\
\hline
\end{tabular}

TABLE 7. The range of estimated noises $(\hat{\sigma})$ and statistical results of maximum likelihood for some time series of passage 5 related to satellites used in the present research in the following three conditions: 1) white noise, 2) White noise + flicker noise, and 3) white noise + random walk noise. 


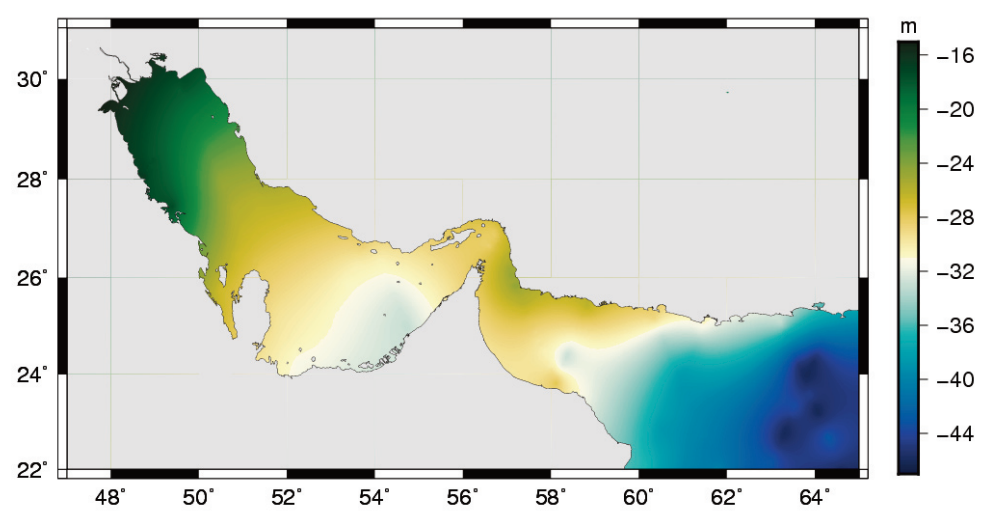

FIGURE 10. The mean sea level (MSL) using altimetry data in meters in the region of the Persian Gulf and Oman Sea considering the white noise condition.

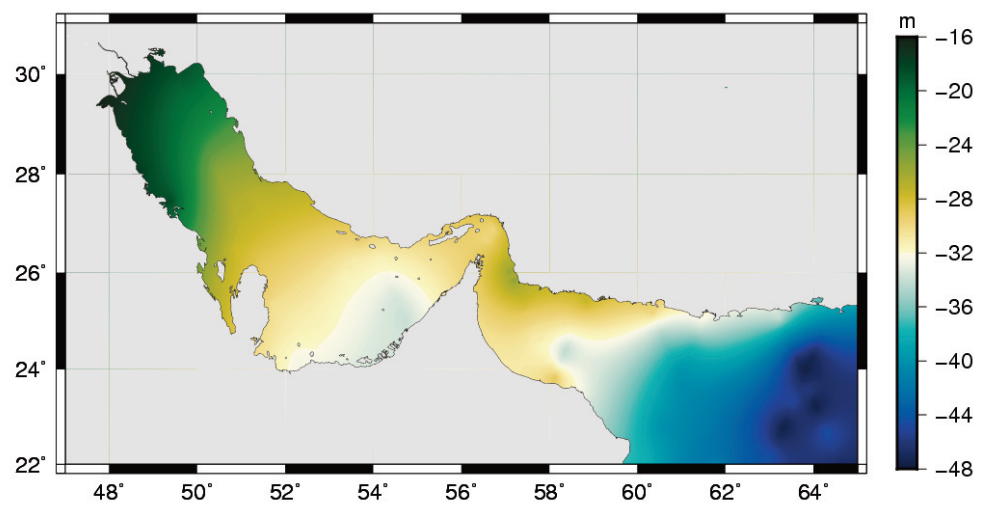

FIGURE 11. The Datum chart using altimetry data in meters in the region of the Persian Gulf and Oman Sea considering the white noise condition.

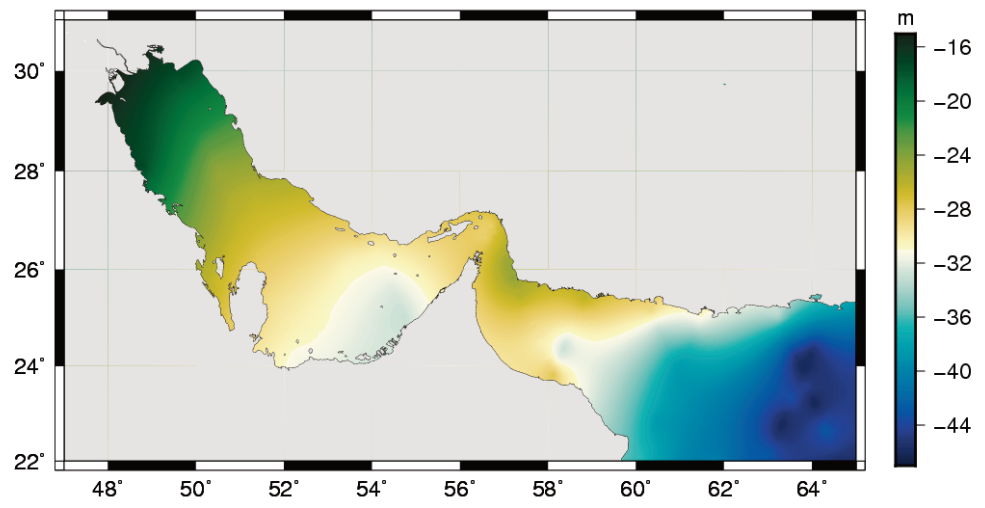

FIGURE 12. The mean sea level (MSL) using altimetry data in meters in the region of the Persian Gulf and Oman Sea considering observations noise.

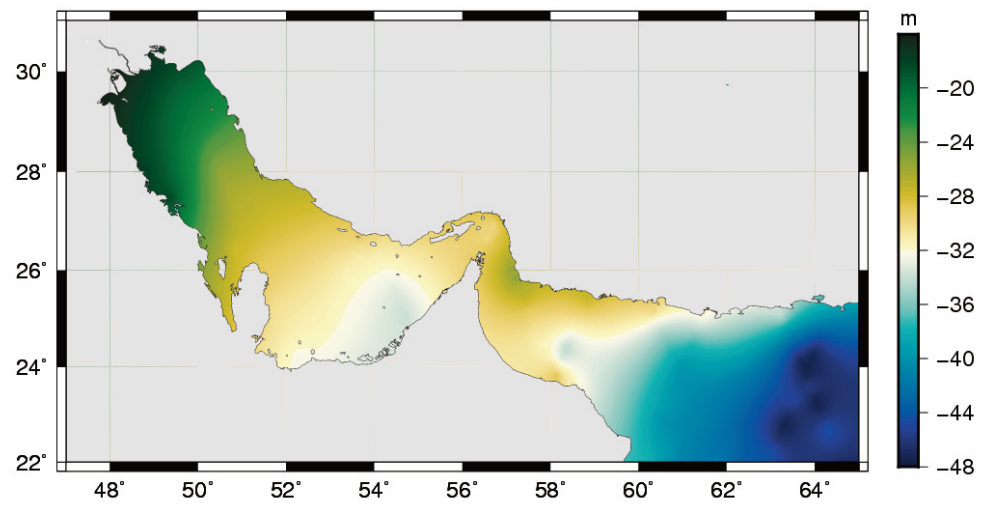

FIGURE 13. The Datum chart using altimetry data in meters in the region of the Persian Gulf and Oman Sea considering observations noise. 
Finally, the obtained difference between two main sea levels and chart datum components have presented in Figures 14 and 15 in two following conditions: 1- considering white noise, and 2- considering the combination of white-flicker noises. The obtained results suggest that using the accurate noise model for observations leads to create an approximate positive difference of 25 centimeters and negative difference of 20 centimeters, and on average an approximate difference of 8 centimeters, are presented in comparison with a condition using observations or unit weight. vations and they are analyzed separately. According to the orbital structure of the altimetry satellites for every point of the satellite foot, a time series was established. Therefore, in 772 effect points of the movement of the satellite and 7 coastal stations in the Persian Gulf and Oman Sea, the mean sea level and the tidal model were determined and mean sea level map, chart datum, and co-domain maps of tidal components $\mathrm{M}_{2}, \mathrm{~S}_{2}, \mathrm{~K}_{1}$, and $\mathrm{O}_{1}$ were presented. With regards to the use of satellite altimetry in the tidal variations modeling of the sea lev$\mathrm{el}$, in the present research, the coastal tidal data were com-

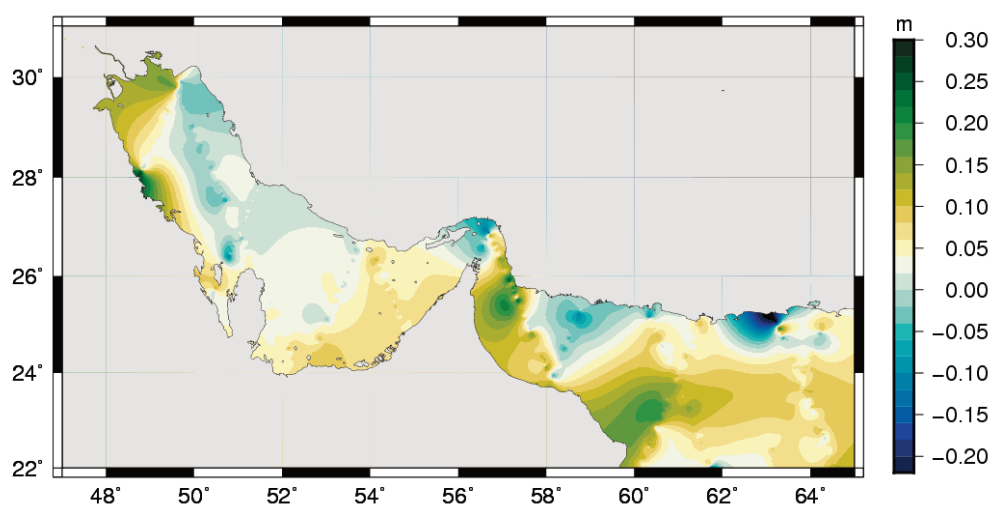

FIGURE 14. The difference of the mean sea level obtained without considering noise, with considering noise, and using a combination of tide gauge and altimetry data in meters in the region of the Persian Gulf and Oman Sea.

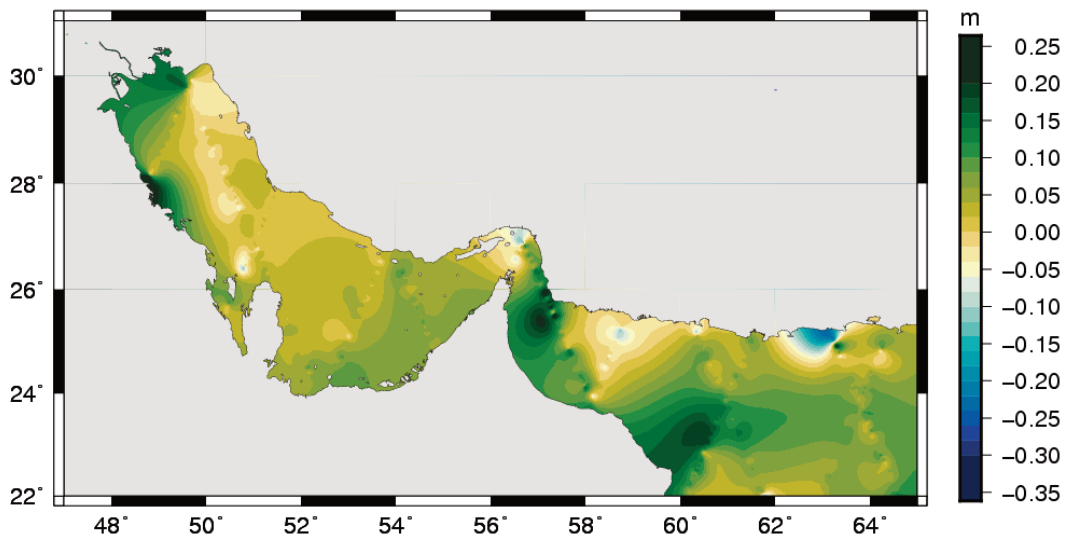

FIGURE 15. The difference of the Datum chart obtained without considering noise, with considering noise, and using a combination of tide gauge and altimetry data in meters in the region of the Persian Gulf and Oman Sea.

\section{CONCLUSION}

In the present research, a tidal variations modeling of the sea level in the Persian Gulf and Oman Sea was conducted using a 22-year period of data from TOPEX-Poseidon, Jason-1, Jason-2 altimeter satellites, and the data from coastal tide gauges. Satellites altimetry observations have been considered as points of the sea level obser- bined with satellite altimetry observations in a point-wise manner. In this method, time series similar to coastal tide gauges are produced from points in the foot of the satellite, and therefore, 772 points in the region have been produced similarly to the coastal tide gauges. The main advantage of the employed method in this study is the simplified tidal analysis models and the possibility of performing the local and regional tide modeling. In other 
words, modeling in the space of time and space can be an appropriate method for global investigations or a major part of the global waters, while the temporal method for tidal investigations can be applied in both small and large scales or even on a global scale. The numerical results indicate the success of this method. Using integration of the data from tidal stations and satellite altimetry, and creating an accurate model for determining the chart datum, decreases significantly the need of performing the tidal observations in hydrographical operations.

Then, the structure of the functional model for examining the noise of the satellite altimetry observations has been investigated. For this purpose, 772 time series over the region have been used. By the assumption that the observations have colored noise, 7 random models were considered for the observations. According to the results, statistical models have been considered as the following combination in the most cases: 1) white, flicker, and random Walk, 2) white, flicker, and autoregressive, 3) white, random walk, and autoregressive, and 4) white, flicker, random walk, and autoregressive; and the variance of the autoregressive and the random walk noises has been estimated with a negative value which, most likely, shows the inappropriateness of the statistical model.

Therefore, in the three remaining conditions, which are white noise, white noise-flicker noise, and white noiserandom walk noise, the evaluation of the results has been conducted using the maximum likelihood technique; based on which, the similarity function for the structure of the second model (white noise-flicker noise) yields the highest value, and it can be concluded that the existing noise in the time series from satellite altimetry observations is a combination of white and flicker noises. Therefore, the combination of the white and the flicker noises can be used as an appropriate statistical model. Obtaining the appropriate functional model for satellite altimetry observations, two important components were analyzed in the first step, i.e. the mean sea level and the chart datum. This analysis has been considered in two conditions: 1) where the observations weight matrix was considered as a unit matrix, or in other words, the existing noise model was considered as a white noise, and 2) where in the observations weight matrix, the matrix is resulted by a combination of white noise-flicker noise. Finally, the obtained difference between two components of the mean sea level and the chart datum was presented in two conditions: 1 - considering white noise, and 2) considering a combination of white noise-flicker noise. Results indicate that using the accurate noise model for observations in maximum possible difference leads to an approximate positive difference of 25 centimeters, an ap- proximate negative difference of 20 centimeters, and on average, an approximate difference of 8 centimeters in comparison with the condition that observations or unit weight are used.

Acknowledgements. The authors would like to thank the AVISO data team for providing the Topex, Jason-1 and Jason-2 altimeter data, and the National Cartographic Center Iran for providing the in situ tide gauge station measurements. Thanks also go to the anonymous reviewers for their constructive comments on an earlier version of this article. We Useful comments of the editor-in-chief, Samantha Royston and anonymous reviewer kindly acknowledged.

\section{REFERENCES}

Ablain, M., J.F. Legeais, P. Prandi, M. Marcos, L. Fenoglio-Marc, H.B. Dieng, J. Benveniste, and A. Cazenave (2017). A Satellite Altimetry-Based Sea Level at Global and Regional Scales, Surv. Geophys., 38, 7-31, doi:10.1007/s10712-016-9389-8.

Amiri-Simkooei, A.R. (2007). Least-squares variance component estimation: theory and GPS applications. PhD thesis, Mathematical Geodesy and Positioning, Faculty of Aerospace Engineering, Delft University of Technology, Delft, Netherlands.

Amiri-Simkooei, A.R. and C.C.J.M. Tiberius (2007). Assessing receiver noise using GPS short baseline time series. GPS Solut., 11(1), 21-35.

Amiri-Simkooei, A.R. (2009). Noise in multivariate GPS position time-series. J. Geod., 83(2), 175-187.

Amiri-Simkooei, A.R., S. Zaminpardaz, M.A. Sharifi (2014). Extracting tidal frequencies using multivariate harmonic analysis of sea level height time series. J Geod., 88, 975-988, doi: 10.1007/s00190014-0737-5.

Amiri-Simkooei, A.R., K. Parvazi, J. Asgari (2017). Extracting tidal frequencies of the Persian Gulf and Oman Sea using multivariate least square harmonic estimation of sea level coastal height observations time series. J. Earth Space Phys., 43, 1, 165-180.

Ardalan, A.A., H. Hashemi-Farahani (2007). A harmonic approach to global ocean tide analysis based on TOPEX/Poseidon satellite, Marine Geophys. Res., 28, 3, 235-255.

Benada, R., G.D.R. Merged (1993). Users handbook. JPL D-11007, Jet Propul. Lab., Pasadena, California.

Birkett, C.M., L. A. K. Mertes, T. Dunne, M. H. Costa, M. J. Jasinski (2002). Surface water dynamics in the 
Amazon Basin: Application of satellite radar altimetry, J. Geophys. Res. Atmosphere, 102, LBA 26-1-LBA 26-21, doi: 10.1029/2001JD000609.

Boon, J.D., K.P. Kevin (1978). Harmonic analysis and tidal prediction by the method of least squares. Va. Inst. Mar. Sci, Gloucester Point, Va, Spec. Rep 186: 49.

Braitenberg, C., P. Mariani, L. Tunini, B. Grillo, and Ildiko Nagy (2011). Vertical Crustal Motions from Differential Tide Gauge Observations and Satellite Altimetry in Southern Italy, J. Geod., 51, 4, 233-244.

Chelton, D.B., J.C. Ries, B.J. Haines, L.L. Fu, P.S. Callahan (2001). Satellite Altimetry and Earth Sciences. A Handbook of Techniques and Applications; edited by Fu L.L. and A. Cazenave, International Geophysics Series, 69, Academic Press, NY, USA.

Cheng, K.C. (2005). Analysis of water level measurements using GPS. Doctoral dissertation, The Ohio State University.

Church, J.A., N.J. White (2011). Sea-level rise from the late 19 th to early 21 st century. Surv. Geophys, 32, 585-602, doi: 10.1007/s10712-011-9119-1.

Church, J.A., White N.J. (2006). A 20th century acceleration in global sea-level rise, Geophys. Res. Lett., 33, 1, doi: 10.1029/2005GL024826

Ellmer, W., Goffinet P. (2006). Tidal Correction Using GPS-Determination of the chart datum. XXIII International FIG Congress, Germany.

Fenoglio-Marc, L. (2002). Long-term sea level change in the Mediterranean Sea from multi-satellite altimetry and tide gauges. Phys. and Chem. Earth, Parts A/B/C, 27(32), 1419-1431.

Frederikse T., R. Riva, M. Kleinherenbrink, Y. Wada, M. Broeke, B. Marzeion (2016). Closing the sea level budget on a regional scale: Trends and variability on the Northwestern European continental shelf. Geophys. Res. Lett., 43(20).

Garcia, D., I. Vigo, B.F. Chao, M.C. Martinez (2007). Vertical crustal motion along the Mediterranean and Black Sea coast derived from ocean altimetry and tide gauge data. In Deformation and Gravity Change: Indicators of Isostasy, Tectonics, Volcanism, and Climate Change, Pure Appl Geophys. 851-863, Birkhäuser Basel.

House, M.R. (1995). Orbital forcing timescales: an introduction. Geological Society, London, Special Publications, 85, 1-18.

Hydrographic Office, (1969). Admiralty manual of hydrographic surveying. Hydrographer of the Navy, London, 2, 134-170.

Hugo, V. Les Misèrables, Fourier analysis and Synthesis.
Kuo, C.Y., C.K. Shum, A. Braun, J.X. Mitrovica (2004). Vertical crustal motion determined by satellite altimetry and tide gauge data in Fennoscandia. Geophys. Res. Lett., 31(1), doi: 10.1029/2003GL019106.

Maheu, C., A. Cazenave, C.R. Machos (2003). Water level fluctuations in the Plata Basin (South American) from Topex satellite altimetry. doi: 10.1029/2002GL016033.

Mangiarotti, S. (2007). Coastal sea level trends from TOPEX-Poseidon satellite altimetry and tide gauge data in the Mediterranean Sea during the 1990s. Geophys. J. Int., 170(1), 132-144.

Marc, L.F., C. Dietz, and E. Groten (2004). Vertical Land Motion in the Mediterranean Sea from Altimetry and Tide Gauge Stations. Marine Geod., 2004, 683-701.

Martin, R.J. and G. J. Broadbent (2004). Chart datum for hydrography. Hydrographic Journal, pp.9-14.

Mitchum, G.T. (1994). Comparison of TOPEX sea surface heights and tide gauge sea levels. J. Geophys. Res.: Oceans, 99(C12), 24541-24553

Nerem, R.S., D.P. Chambers, C. Choe and G.T. Mitchum (2010). Estimating Mean Sea Level Change from the TOPEX and Jason Altimeter Missions, Marine Geod., 33, 435-446, doi: 10.1080/01490419.2010.491031.

Pugh, D. and P. Woodworth (2014). Sea-level science: understanding tides, surges, tsunamis and mean sea-level changes. Cambridge University Press.

Richter, K., J.E.O. Nilsen, H. Drange (2012). Contributions to sea level variability along the Norwegian coast for 1960-2010. J. Geophys. Res. 117, doi:10.1029/2011JC007826.

Rosmorduc V., J. Benveniste, O. Lauret, C. Maheu, M. Milagro, N. Picot (2009). Radar Altimetry Tutorial. ESA, Europe, 112-128.

Tapley, B.D., J.C. Ries, G.W. Davis, R.J. Eanes, B.E.,Schutz, C.K. Shum, M. M. Watkins, J.A. Marshall, R.S. Nerem, B.H. Putney, S.M. Klosko, S.B. Luthcke, D. Pavlis, R.G. Williamson, N.P. Zelensky (1994). Precision orbit determination for TOPEX/POSEIDON. J. Geophys. Res, 99, C12: 24, 383-404.

Teunissen, P.J.G. (1988). Towards a least-squares framework for adjusting and testing of both functional and stochastic model. Internal research memo, Geodetic Computing Centre, Delft. A reprint of original 1988 report is also available in 2004, 26.

Teunissen, P.J.G. (2000). Testing theory: an introduction. Delft University Press, Website: http://www.vssd.nl. Series on Mathematical Geodesy and Positioning 
Teunissen, P.J.G., D.G. Simons, C.C.J.M. Tiberius (2005). Probability and observation theory, Faculty of Aerospace Engineering, Delft University, Delft University of Technology, Lecture notes AE2-E01.

Vanicek P., E. Krakiwsky (1991). Lecture note. Geodynamics for geodesists. University of New Brrunswick Canada.

Wahr, J. (1995). Earth Tides. Global Earth Physics. A Handbook of Physical Constants, AGU Reference Shelf, 1, 40-46.

Wang, Y. (2004). Ocean Tide Modeling in Southern Ocean, Department of civil and Environmental Engineering and Geodetic Science. Report No.471, The Ohio State University: Columbus. 